\title{
Clinical Characteristics and Current Treatment of Age-Related Macular Degeneration
}

\author{
Yoshihiro Yonekawa and Ivana K. Kim \\ Retina Service, Department of Ophthalmology, Massachusetts Eye and Ear Infirmary, Harvard Medical \\ School, Boston, Massachusetts 02114 \\ Correspondence: Ivana_Kim@meei.harvard.edu
}

\begin{abstract}
Age-related macular degeneration (AMD) is a multifactorial degeneration of photoreceptors and retinal pigment epithelium. The societal impact is significant, with more than 2 million individuals in the United States alone affected by advanced stages of AMD. Recent progress in our understanding of this complex disease and parallel developments in therapeutics and imaging have translated into new management paradigms in recent years. However, there are many unanswered questions, and diagnostic and prognostic precision and treatment outcomes can still be improved. In this article, we discuss the clinical features of AMD, provide correlations with modern imaging and histopathology, and present an overview of treatment strategies.
\end{abstract}

\begin{abstract}
$\mathrm{A}_{\mathrm{a}}^{\mathrm{ge}}$ ge-related macular degeneration (AMD) is multifactorial maculopathy characterized by late-onset progressive neurodegeneration of photoreceptors and retinal pigment epithelium (RPE) (Miller 2013). AMD is the leading cause of irreversible blindness in older individuals of industrialized nations. In the United States alone, it was estimated that more than 9 million people had AMD in 2000, of which nearly 2 million were in advanced stages (Friedman et al. 2004). These figures were projected to more than double by 2020. The World Health Organization indicates that AMD ranks third after cataract and glaucoma as a leading cause of blindness globally (WHO 2013).

AMD is typically classified into two phenotypic categories: nonneovascular (dry; nonexudative), and neovascular (wet; exudative). Non-
\end{abstract}

neovascular AMD is characterized by small, yellow, round deposits called drusen at the level of the RPE. Other changes include focal RPE hyperpigmentation and atrophy. When atrophic areas become confluent, the condition is termed geographic atrophy, which is considered an advanced stage of nonexudative AMD. Neovascular AMD is also an advanced form of AMD, and occurs when abnormal blood vessels grow beneath the neurosensory retina or RPE.

Although only $10 \%$ of patients with AMD have the neovascular form, it formerly caused $\sim 90 \%$ of AMD-related blindness (Ferris et al. 1984). The past decade has seen revolutionary advances in the treatment of neovascular AMD with anti-vascular endothelial growth factor (VEGF) agents. Numerous basic, translational, and clinical studies are underway to further im-

Editors: Eric A. Pierce, Richard H. Masland, and Joan W. Miller

Additional Perspectives on Retinal Disorders: Genetic Approaches to Diagnosis and Treatment available at

www.perspectivesinmedicine.org

Copyright (C) 2015 Cold Spring Harbor Laboratory Press; all rights reserved; doi: 10.1101/cshperspect.a017178

Cite this article as Cold Spring Harb Perspect Med 2015;5:a017178 
prove these outcomes and lessen treatment burden.

\section{RISK FACTORS}

\section{Demographic Risk Factors}

Age is the strongest risk factor for development and progression of all forms of AMD. The Eye Diseases Prevalence Research Group pooled data from seven regional population-based studies and applied the rates to the 2000 United States Census (Friedman et al. 2004). The prevalence of intermediate AMD (at least one druse $125 \mu \mathrm{m}$ or larger in one or both eyes) was $5.4 \%$ in 60- to 64-year old people, $7.4 \%$ in 65-69-year old people, $10.2 \%$ in $70-74$-year old people, $14.1 \%$ in 75 - to 79 -year old people, and $23.6 \%$ in those 80 or older. The respective rates of geographic atrophy were $0.3 \%, 0.5 \%, 0.9 \%, 1.8 \%$, and $6.9 \%$. The respective rates of neovascular AMD were $0.4 \%, 0.6 \%, 1.2 \%, 2.2 \%$, and $8.2 \%$.

Advanced AMD (neovascular AMD and geographic atrophy) has been shown to be more frequent in Caucasians. In the Baltimore Eye Study (BES), 30\% of bilateral blindness was caused by AMD in Caucasians, whereas none of the African Americans became bilaterally blind from AMD (Sommer et al. 1991). The Eye Diseases Prevalence Research Group pooled data from the Baltimore Eye Study, Barbados Eye Study, and the Salisbury Eye Evaluation Project, and showed that African Americans, similar to Caucasians, have a steady increase in large drusen and advanced AMD with age (Friedman et al. 2004). However, the exponential increase later in life is not observed in African Americans. Latinos appear to have high prevalence of early AMD but not advanced AMD (Varma et al. 2004), and Asians have relatively similar rates to Caucasians (Kawasaki et al. 2010).

\section{Environmental Risk Factors}

Smoking is an important modifiable risk factor for AMD. The Age-Related Eye Disease Study (AREDS) was a randomized study that examined the effects of high-dose antioxidants and zinc as a treatment for AMD. From the 4519 subjects enrolled in the risk factor analyses, the AREDS showed that those who had ever smoked had almost double the risk for neovascular AMD compared with those who had never smoked (AREDS-Study-Group 2000). The Physicians' Health Study involved 21,157 participants and showed that current smokers of 20 or more cigarettes per day had double the risk of developing AMD compared with neversmokers (Christen et al. 1996). The Nurses' Health Study analysis of 31,843 women showed similar findings (Seddon et al. 1996).

\section{Systemic Risk Factors}

The association between AMD and cardiovascular disease has been observed, but it remains equivocal whether cardiovascular disease is an independent risk factor for AMD. Some large studies have shown that carotid atherosclerotic lesions increase the risk for AMD (Vingerling et al. 1995), although others have not (Klein et al. 2013). Cerebrovascular disease overall does not seem to be a strong risk factor (Goldberg et al. 1988; Eye-Disease-Case-ControlStudy-Group 1992; Klein et al. 1993; Vinding 1995; Vingerling et al. 1995). A larger number of epidemiological studies have implicated hypertension as a risk factor (Sperduto and Hiller 1986; Goldberg et al. 1988; Hyman et al. 2000; Klein et al. 2003; van Leeuwen et al. 2003) compared to those that did not (Eye-Disease-CaseControl-Study-Group 1992; Klein et al. 1993). Studies investigating gene-environment interactions may provide a better understanding of the role of cardiovascular disease in AMD (Feehan et al. 2011).

\section{CLINICAL FEATURES}

\section{Normal Aging}

The macula undergoes a spectrum of subclinical changes in the normally aging eye. In a subset of individuals, these changes progress to more pathologically significant findings and manifest clinically as AMD (Zarbin 2004). Healthy young maculae normally have a sharp foveal light reflex on biomicroscopy, caused by the concave shape of the fovea. As the macula 
ages, this reflex becomes blunted, possibly owing to the decrease in photoreceptor density, shallowing of the foveal pit, and enlargement of the capillary-free zone (Laatikainen and Larinkari 1977). Several small, well-defined drusen will usually be present in the elderly (Klein et al. 1992). Irregularity of the RPE also causes a stippled background of varying degrees.

Morphologic changes are abundant in the normally aging macula. The photoreceptor drop-out during aging is mostly caused by loss of rods (Curcio et al. 1993); foveal cone density appears to remain constant until beyond the ninth decade (Feeney-Burns et al. 1990; Curcio et al. 1993). The outer segments of the rods become disorganized and may accumulate at the apices of the RPE (Feeney-Burns et al. 1990).

The RPE is vulnerable to age-related changes because it is a nonreplicating tissue. For the entire lifespan of the eye, it continually engulfs photoreceptor discs and material from surrounding photoreceptors and RPE cells; it also undergoes autophagy of its cellular contents. Undigested material remains as lipofuscin, a granular lipid-containing pigment containing a mixture of fluorescent cellular byproducts, which exponentially increases with aging (Feeney-Burns et al. 1980). As lipofuscin accumulates in the RPE, cytoplasmic space and metabolic capacity become limited, and the RPE deteriorates over time (Panda-Jonas et al. 1996).

The basal infoldings of the RPE are also reduced from striated cuticular or basal laminar deposits (BLamD) that start to accumulate between the RPE basal plasma membrane and the underlying basement membrane. BLamD are uniformly seen by the seventh decade of life (Sarks 1976) and are composed of lipoproteins and amyloid $\beta$. They are considered normal aging changes if they are focal lesions (Miller 2013). Clinically, early forms of BLamD can appear as small, well-circumscribed, "hard" drusen. They may have a translucent appearance if clustered together and viewed with retroillumination on biomicroscopy for middle-aged individuals. However, BLamD are often not directly visible on clinical funduscopy and represent more of a histopathologic finding. An eye with early BLamD typically has a normal clinical fundus appearance. BLamD are distinct from basal linear deposits (BLinD), which are specific histopathologic findings of AMD. Whereas BLamD accumulate between the RPE plasma membrane and the RPE basement membrane (in the sub-RPE space), BLinD are located deeper beneath the RPE basement membrane at the level of Bruch's membrane (Miller 2013).

\section{Early and Intermediate AMD}

The aforementioned morphologic changes of the aging fundus are clinically benign. There are several features that characterize the tipping point toward the pathologic state of AMD. In AMD with RPE degeneration, the patchy BLamD seen in normal aging develop an overlying layer of a diffuse, thick, amorphous, hyalinized material, which can become nodular elevations (Bressler et al. 1994). Clinical correlation of this late form of BLamD has not been accurately established, but its presence can be inferred by pigmentary changes (Sarks et al. 2007). Focal areas of hyperpigmentation correlate histologically with RPE hypertrophy and pigmented cells that migrate to the sub-RPE and subretinal space. These pigmented cells may also migrate into the outer nuclear layer, and represent compromised RPE cells that can no longer support photoreceptors.

BLinD form layers of membranous debris within Bruch's membrane, between the RPE basement membrane and the inner collagenous layer. BLinD are thought to be primarily composed of lipoprotein particles (Sarks et al. 1980). These layers accumulate and clinically appear as soft drusen that are characteristic of AMD (Fig. 1) (Sarks et al. 2007). Multilayered BLinD cause a separation of the RPE from Bruch's membrane, and blood, serous fluid, and choroidal neovascular membranes can make their way into this space. However, BLinD can also accumulate as focal aggregations of basal mounds between the RPE basement membrane and plasma membrane (Sarks et al. 1988). BLinD do not manifest as drusen in this type of accumulation, but may cause pigmentary changes and primary geographic atrophy without drusen on clinical examination (Sarks et al. 2007). 


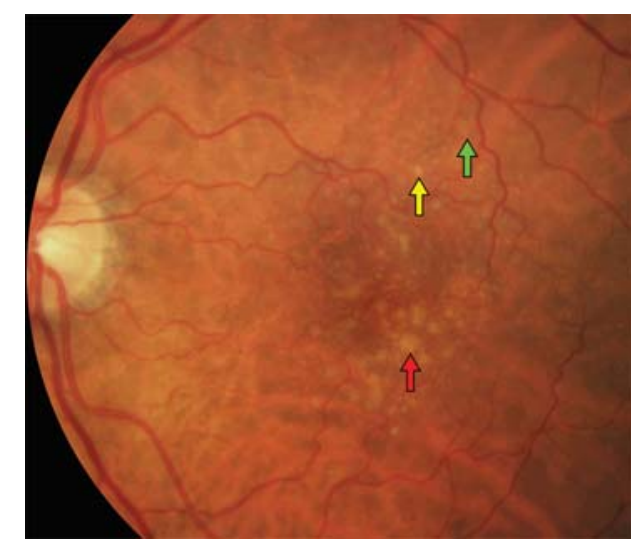

Figure 1. Color fundus photograph of drusen in nonneovascular age-related macular degeneration. There are small $(<63 \mu \mathrm{m}$, green arrow), intermediate (63$124 \mu \mathrm{m}$, yellow arrow), and large $(\geq 125 \mu \mathrm{m}$ [average diameter of retinal venule at the optic disc margin], red arrow) drusen.

\section{Reticular Pseudodrusen}

Reticular pseudodrusen (or subretinal drusenoid deposits) represent a subphenotype of AMD that was first identified on blue-light (red-free) fundus photography (Mimoun et al. 1990). They clinically appear as yellowish, faint, interlacing networks that most commonly occur along the arcades, and do not fluoresce on fluorescein angiography. Fluorescein sodium is a yellow, synthetic salt dye. Its molecules excite when exposed to blue light (wavelengths 485$500 \mathrm{~nm})$, and emit a green light $(520-535 \mathrm{~nm})$ as it returns to its original state. For retinal imaging, fluorescein is injected intravenously, and serial fundus photographs or videos are taken using a green filter.

Imaging with optical coherence tomography (OCT), particularly spectral domain OCT, (SD-OCT) has been shown to be effective at detecting reticular pseudodrusen. OCT is a noncontact imaging apparatus that projects infrared light onto the retina and detects backscattered light, which is converted into highresolution cross-sectional images that can be reconstructed into three dimensional thickness maps. SD-OCT systems have scanning rates of 20,000-40,000 axial scans per sec, with axial resolution of $5 \mu \mathrm{m}$. Hyperreflective materials include the nerve fiber layer, plexiform layers, RPE, and blood, whereas the nuclear layers, photoreceptors, and fluid appear hyporeflective. In patients with AMD, intraretinal fluid, subretinal fluid, and pigment epithelial detachments can be visualized with exquisite detail not previously possible with biomicroscopy.

SD-OCT imaging of reticular pseudodrusen shows numerous drusenoid deposits above the RPE in the subretinal space (Fig. 2) (SchmitzValckenberg et al. 2010; Zweifel et al. 2010). This is contrary to previous histopathologic studies that localized the changes to the choroid. The origin of these lesions remains unclear, but may represent direct photoreceptor damage. Reticular pseudodrusen were initially associated with neovascular AMD (Arnold et al. 1995; Cohen et al. 2007), but recent studies show that they also represent a risk factor for progression to geographic atrophy (Klein et al. 2008b; Pumariega et al. 2011).

\section{Geographic Atrophy}

Geographic atrophy is a late manifestation of nonneovascular AMD and is clinically characterized by a sharply delineated area of depigmentation revealing the underlying choroidal vasculature (Fig. 3). Most cases of geographic atrophy develop in areas previously noted to have large drusen. The life cycle of long-standing drusen is commonly characterized by the initial development of hyperpigmentation, followed by hypopigmentation as the drusen regress, and finally geographic atrophy (Klein et al. 2008a). In the AREDS, sites that developed geographic atrophy were preceded by drusen in $100 \%$, large drusen in $96 \%$, confluent drusen in 94\%, hyperpigmentation in $96 \%$, hypopigmentation in $82 \%$, and refractile bodies in $23 \%$ of patients. The time of progression to geographic atrophy varied from $5.9 \mathrm{yr}$ for confluent drusen to $2.5 \mathrm{yr}$ for hypopigmentation or refractile bodies. The spread of atrophy can progress around the fovea in a continuous ring or in several patches perifoveally. Geographic atrophy usually does not affect the center of vision (fixation) until later stages.

Geographic atrophy on fluorescein angiography appears as sharply demarcated areas of 


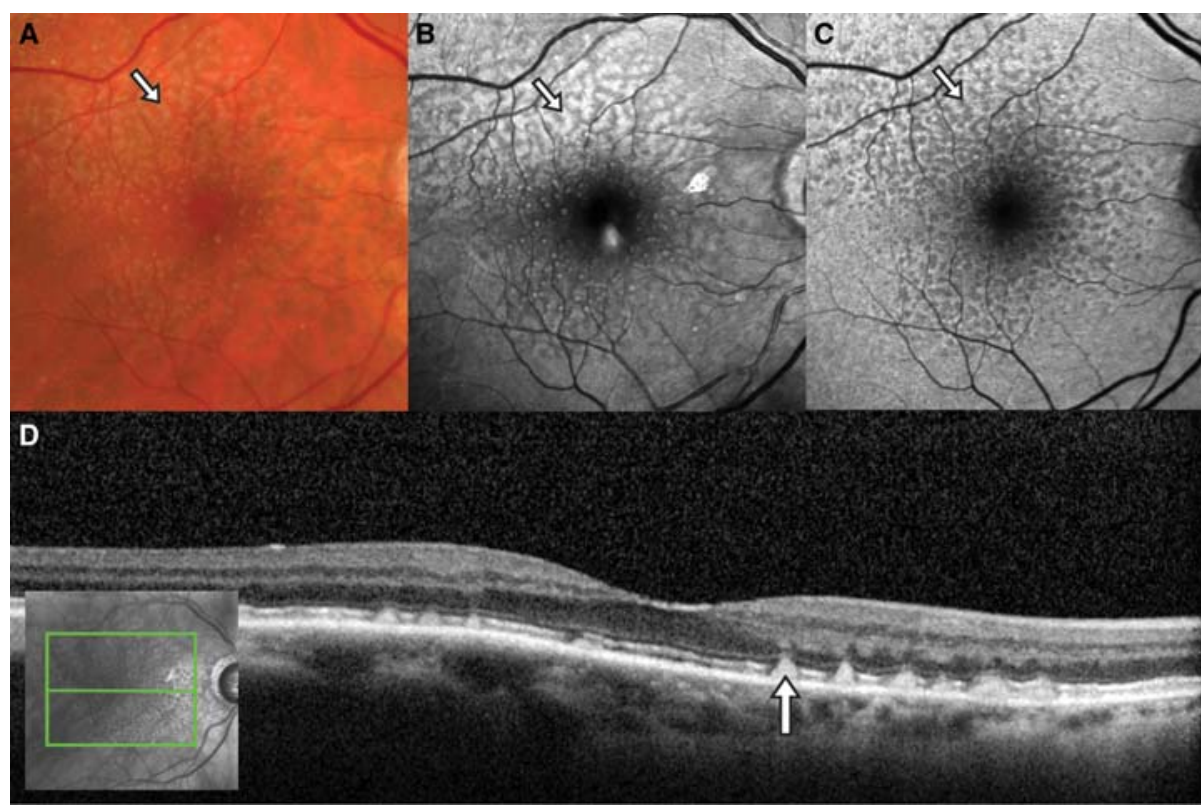

Figure 2. Multimodal imaging of reticular pseudodrusen (arrows). (A) Color fundus photograph showing yellowish interlacing networks that extend to the vascular arcades. $(B)$ Red-free fundus photography most clearly demonstrates the pseudodrusen as bright spots and the interlacing networks that appear hyporeflective. $(C)$ Fundus autofluorescence shows that the lesions are hypoautofluorescent. (D) Spectral-domain optical coherence tomography demonstrates that the pseudodrusen are located between the retina and retinal pigment epithelium (RPE), rather than the sub-RPE localization of typical drusen.

hyperfluorescence during the transit phase because of transmission from the underlying choroidal vasculature. On SD-OCT, areas of geography atrophy are characterized by loss of the external limiting membrane, inner/outer segment junction (or ellipsoid zone), and the RPE-Bruch's membrane complex. Because of the lack of RPE, there is often enhancement of the underlying choroidal reflectivity.

Fundus autofluorescence has been popularized as an accurate tool for monitoring the progression of geographic atrophy (Fig. 3). Autofluorescence refers to light-emitting properties of certain tissues in their natural state. The main fluorophore of RPE lipofuscin is A2E, a pyridinium bisretinoid conjugate containing two vitamin A aldehyde molecules and one ethanolamine molecule. Lipofuscin can respond to excitation by wavelengths $300-500 \mathrm{~nm}$, with emission of $620-630 \mathrm{~nm}$. Autofluorescence can be captured with a fundus camera equipped with the appropriate filters or more commonly now with a scanning laser ophthalmoscope. Lesions with increased lipofuscin result in hyperautofluorescence, and a decrease of lipofuscin or absence of RPE results in hypoautofluorescence. In geographic atrophy, the atrophic areas appear as sharply demarcated areas of loss of autofluorescence, corresponding to areas of RPE loss and therefore lack of lipofuscin. Studies have demonstrated that hyperautofluorescence of the junction between atrophic and nonatrophic areas is predictive of subsequent enlargement of the geographic atrophy, and that patches of hyperautofluorescence in the posterior pole precede new areas of atrophy (Holz et al. 2001; Schmitz-Valckenberg et al. 2006). This is thought to be from lipofuscin overload in dysfunctional RPE cells.

\section{Neovascular AMD}

Choroidal neovascularization $(\mathrm{CNV})$ is the defining characteristic of neovascular AMD. The 


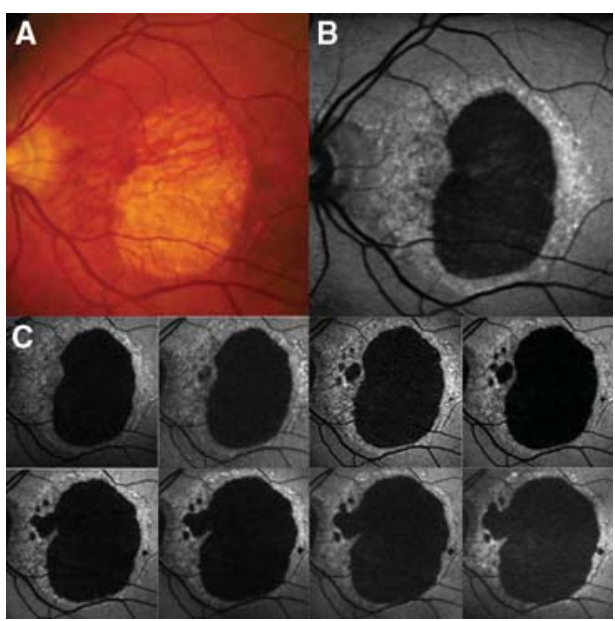

Figure 3. Geographic atrophy in advanced nonneovascular age-related macular degeneration. $(A)$ Color fundus photograph of central geographic atrophy. (B) The corresponding fundus autofluorescence delineates the kidney-shaped area of atrophy as hypoautofluorescent (dark). However, it also shows that the surrounding clinically normal-appearing retina is hyperautofluorescent, which indicates an accumulation of lipofuscin. $(C)$ Over the course of the next 6 years, the geographic atrophy gradually extends to the areas that were hyperautofluorescent in $(B)$. (Reprinted, with permission, from Schmitz-Valckenberg et al. 2009.)

CNV grows through breaks in Bruch's membrane and expands beneath the RPE (type I $\mathrm{CNV}$ ), or between the RPE and photoreceptors (type II CNV). The incompetent endothelial cells of the new vasculature cause fluid leakage and accumulation of proteins and lipids. The new friable vessels are also prone to hemorrhage. Type I CNV typically manifests clinically as a fibrovascular retinal pigment epithelial detachment (PED). The typical clinical appearance of type II CNV is a gray-green lesion beneath the retina with overlying retinal thickening. Subretinal and intraretinal fluid, lipid exudates, and subretinal hemorrhage may accompany both types of CNV.

Fluorescein angiography is the gold standard for diagnosing CNV. Angiography can provide valuable data in distinguishing CNV from other potential causes of retinal edema such as diabetic macular edema and pseudophakic cys- toid macular edema. The angiographic term "classic" CNV refers to a well-demarcated area of hyperfluorescence that manifests in the early phases of the angiography. In the intermediate and late phases, there is typically intense leakage from the lesion (Fig. 4A-C). This pattern correlates with type II CNV. "Occult" (type I) CNV has two patterns: (1) fibrovascular PEDs or (2) leakage from an undetermined source, characterized by an ill-defined focus of choroidal leakage without identifiable classic $\mathrm{CNV}$ or fibrovascular PED (Fig. 4D-F).

PEDs are focal areas that appear as elevations of the RPE on bimicroscopy. Visual acuity is relatively preserved compared with neurosensory detachments, as long as there is no overlying neurosensory detachment. There are several different types of PED: fibrovascular, drusenoid, and serous. Fibrovascular PEDs are associated with underlying $\mathrm{CNV}$, whereas drusenoid PEDs are not, and serous PEDs may be seen in both scenarios.

Fibrovascular PEDs demonstrate early mottled or granular hyperfluorescence on fluorescein angiography with mild late leakage. Fibrovascular PEDs may be associated with blood. Hemorrhage localized to the sub-RPE space of the PED will appear as dark greenish-red elevations, but the blood may also track into the subretinal space and, rarely, into the vitreous. Patients with predominantly hemorrhagic PEDs often present with poor visual acuity (Bressler et al. 2004).

Drusenoid PEDs are slowly enlarging; shallow elevations of the RPE with scalloped borders that are thought to develop from the coalescence of soft drusen. They have better short-term visual outcomes compared to the other types of PEDs (Hartnett et al. 1992), but $42 \%$ of eyes with drusenoid PEDs eventually progressed to either geographic atrophy or neovascular AMD by $5 \mathrm{yr}$ in the AREDS, with associated decline in vision (Cukras et al. 2010). On fluorescein angiography, there is delayed, gradual, mild staining deep to the RPE with no leakage, and drusenoid PEDs do not become intensely fluorescent as do serous PEDs. Compared with fibrovascular PEDs, drusenoid PEDs are smaller, shallower, and have irregular borders. 


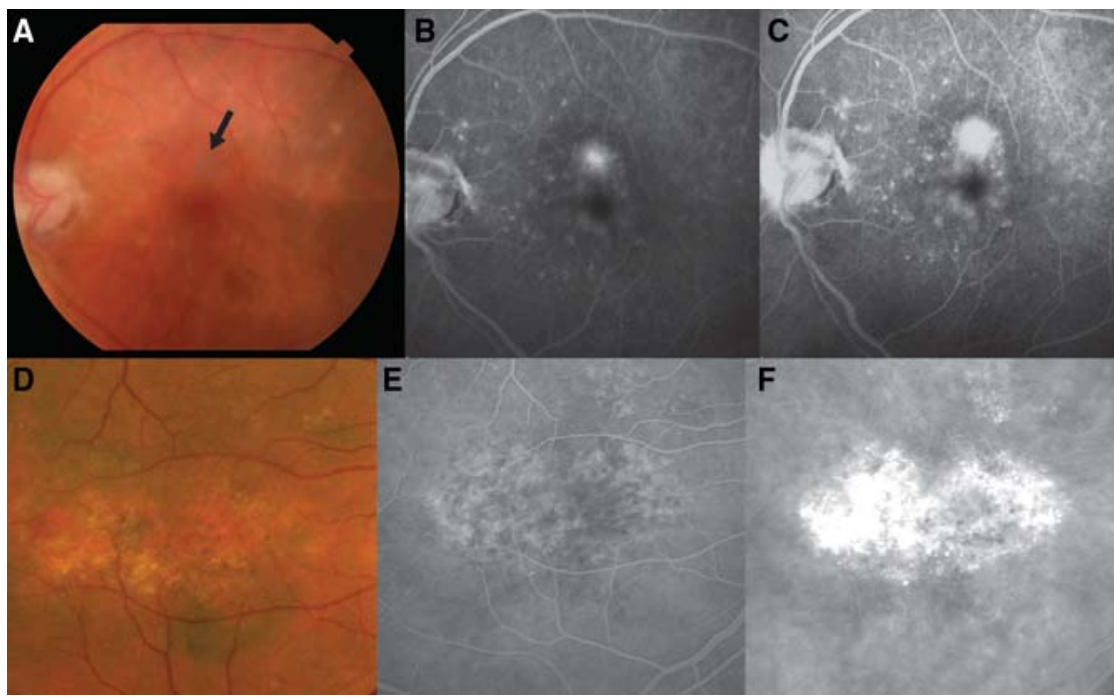

Figure 4. Classic and occult choroidal neovascularization (CNV) in neovascular age-related macular degeneration. (A) Color fundus photograph shows a greenish lesion deep to the retina (arrow). (B) Fluorescein angiography shows a focal well-demarcated hyperfluorescence of the CNV that leaks in later $(C)$ frames. There are also scattered drusen that also appear bright. $(D)$ Color fundus photograph shows drusen, pigmentary changes, and a diffusely mottled appearance of the retinal pigment epithelium. Fluorescein angiography demonstrates an ill-defined area of hyperfluoresence $(E)$ that leaks diffusely in mid to late frames $(F)$.

Serous PEDs are sharply demarcated, domeshaped RPE elevations. Fluorescein pools in the lesions briskly, uniformly, and intensely, without leakage. These lesions may interfere with visualization of underlying CNV on fluorescein angiography. OCT and indocyanine green angiography (see section on Polypoidal Choroidal Vasculopathy) may be useful adjunctive tools in such cases. The natural history of all types of PEDs involves eventual collapse. Geographic atrophy can develop after the collapse of PEDs, especially with large drusenoid PEDs. Tears of the RPE may mimic geographic atrophy, but the former is usually characterized by fluid overlying the tear and intense hyperfluorescence on fluorescein angiography.

OCT, especially SD-OCT, provides detailed anatomical characterization of eyes with neovascular AMD. The ease and speed of acquiring the images has made it the most frequently used imaging modality to follow AMD patients. $\mathrm{CNV}$ appears as hyperreflective membranes deep to the RPE or in the subretinal space with associated intraretinal or subretinal fluid. Three-di- mensional OCT reconstructions of CNV lesions have been shown to correlate with fluorescein findings (Malamos et al. 2009). One study showed that fluorescein angiography is superior to time-domain OCT in detecting new-onset CNV (Do et al. 2012), but it is not yet known whether this holds true with the higher-resolution SD-OCT (Khurana et al. 2010).

SD-OCT allows high-resolution imaging of the exudative fluid associated with CNV (Sayanagi et al. 2009). PEDs appear as elevation of the RPE from Bruch's membrane. Serous PEDs appear dome-shaped, with homogeneously hyporeflective material (optically empty) and good visualization of the underlying choroidal structures. Drusenoid PEDs typically have smooth surface contours with homogeneously hyperreflective material within the PED. Fibrovascular PEDs can have surfaces that are either smooth or irregular, and have heterogeneous material within the PED (Fig. 5). OCT software algorithms are under development to allow automated classification of the type of PED (Lee et al. 2012a). 


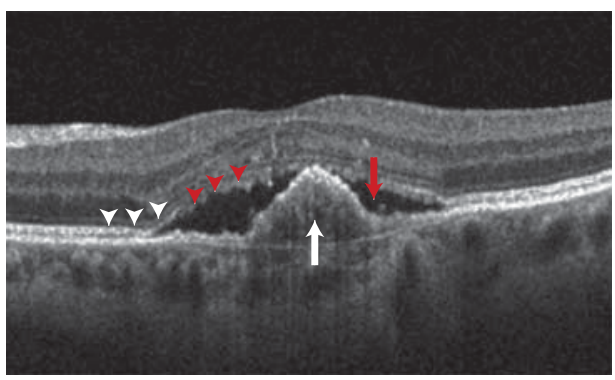

Figure 5. Spectral-domain optical coherence tomography of a central fibrovascular pigment epithelial detachment (white arrow) with overlying subretinal fluid (red arrow). The inner-segment/outer-segment junction of the photoreceptors (white arrowheads) has become disrupted in the area overlying the lesion (red arrowheads).

Subretinal fluid on SD-OCT appears as darkly hyporeflective spaces beneath the retina, and intraretinal fluid commonly presents as hyporeflective cystic spaces within the retina. Degenerative cystic changes can be seen in longstanding disease, but these findings do not signify active exudation. These cystic lesions are often sharply demarcated and static. Outer retinal tubulation is another finding in advanced AMD, consisting of round or ovoid, relatively hyporeflective spaces with hyperreflective borders (Fig. 6) (Zweifel et al. 2009). These structures are thought to represent cross sections of tubular branches of degenerating photoreceptors. It is important to recognize degenerative cysts and outer retinal tubulation, because these findings may be misinterpreted as active intraretinal fluid and may prompt unnecessary treatment.

The end-stage result of neovascular AMD is a subretinal, fibrovascular, disciform scar that causes deterioration of the overlying sensory retina. Disciform scars usually appear white to yellow and may have areas of hyperpigmentation caused by RPE hyperplasia. Depending on the extent of RPE hyperplasia within the scar, angiography may show staining or blockage. These fibrovascular scars may continue to grow, with new neovascularization along the borders of the lesions. The late-stage appearance can be very variable. Some heavily pigmented, elevated scars may mimic choroidal tumors, whereas others may develop substantial lipid deposition to mimic Coats' disease and rarely, massive exudation of fluid may cause a large serous retinal detachment.

\section{Polypoidal Choroidal Vasculopathy}

Polypoidal choroidal vasculopathy (PCV) is proposed to be a variant of type I CNV (Imamura et al. 2010). Abnormal tubular and polypshaped vascular channels deep to the RPE characterize PCV. It is generally seen in Asian, Hispanic, and black populations. One study from Japan showed that approximately half of patients with neovascular AMD had PCV (Maruko et al. 2007). It is now recognized that PCV also affects white populations, albeit to a lesser degree (Imamura et al. 2010). PCV occurs more often in younger patients, may not always be associated with drusen, and often contains a hemorrhagic component. Large polyps may be visible on clinical examination, but fundoscopy,

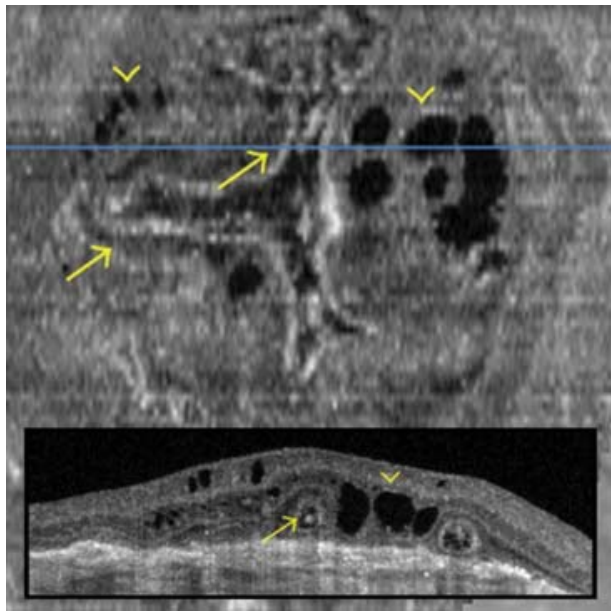

Figure 6. Outer retinal tubulation (arrows) and degenerative cystic cavities (arrowheads) located above a fibrovascular scar. The "en face" optical coherence tomography (OCT) demonstrates that the tubulations form a branching network. The corresponding B-scan OCT (inset) shows the tubulations as round and ovoid hyporeflective spaces with a ring of hyperreflectivity, and the degenerative cysts as sharply demarcated cavities. (Adapted, with permission, from Wolff et al. 2012. 


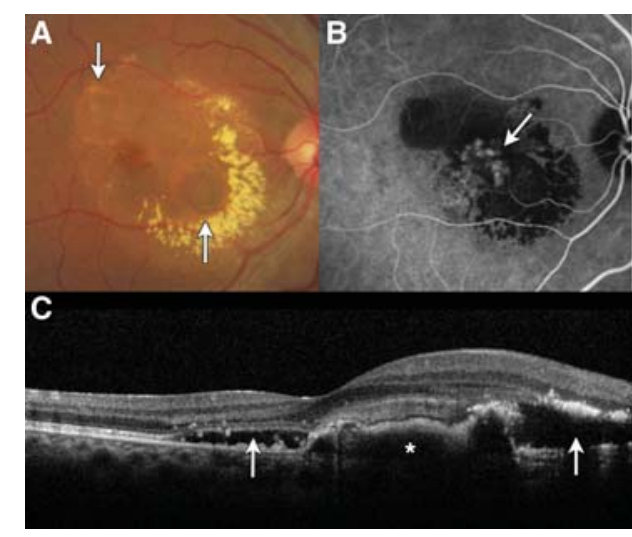

Figure 7. Polypoidal choroidal vasculopathy. (A) Color fundus photograph showing two pigment epithelial detachments (PED; arrows) with circinate exudation and subretinal fluid. (B) Indocyanine green angiography showing hyperfluorescent polypoidal lesions in the choroidal vasculature (arrow). (C) The corresponding spectral domain optical coherence tomography shows the subretinal fluid (arrows) and elevation of the retinal pigment epithelium (asterisk). (Adapted, with permission, from Yonekawa 2013.)

OCT, and fluorescein angiography are often not able to distinguish PCV from typical AMD. Indocyanine green (ICG) angiography is the definitive method to image the polypoidal vascular structures in the choroid (Fig. 7).

ICG angiography uses a high-molecular weight dye with infrared emission (830-840 $\mathrm{nm})$. A confocal laser applies an infrared 790 $\mathrm{nm}$ light beam and photographs/video are taken similarly to fluorescein angiography. The ICG dye has strong protein-binding properties, and the large size of the ICG-protein complexes reduces the amount of extravasation from the choriocapillaris, which allows superior visualization of the choroidal circulation. Compared with the visible light used for fluorescein, the infrared spectrum allows deeper penetration through the retina and RPE, as well as through media opacities such as cataract and hemorrhage.

\section{Retinal Angiomatous Proliferation}

Retinal angiomatous proliferation is another variant of neovascular AMD that is characterized by intraretinal neovascularization. Other names for this entity include "retinal angiomatous lesion," "deep retinal vascular anomalous complex," "retinal anastomosis to the lesion," "retinal vascular anomalous complex," "retinal choroidal anastomosis," and "type III neovascularization" (Yannuzzi et al. 2001; Freund et al. 2008). As the multiple names suggest, there is much debate over its pathogenesis and natural history. Yannuzzi and colleagues introduced the most commonly used term "retinal angiomatous proliferation (RAP)" in 2001 to describe a neovascular process that originated within the neurosensory retina (Yannuzzi et al. 2001). The intraretinal neovascularization was then thought to extend posteriorly into the subretinal space, create a PED, and merge with underlying type I CNV. Gass and colleagues proposed an alternative theory in 2003, describing a process in which the initial pathologic stimulus is an occult type I CNV with associated superficial retinal hemorrhages between the outer retinal capillaries and the CNV (Gass et al. 2003). This was thought to be followed by choroidal-retinal anastomoses, resulting in a "piggy-back" type II CNV overlying the type I CNV.

Clinically, RAP lesions are commonly characterized by intraretinal hemorrhage overlying a retinal vessel that acutely dives in toward the RPE (Fig. 8). Lesions are often located in the paramacular area. Angiomatous tissue with surrounding capillary telangiectasia and dilated perfusing arterioles or draining venules can be seen in early stages. Subretinal fluid and/or hemorrhage are seen if type II neovascularization has occurred. ICG plays an important role in distinguishing RAP from PCV and occult CNV. ICG angiography allows visualization of the anastomotic connections between the retinal and choroidal circulation characteristic of RAP. However, anastomotic connections may also be seen in end-stage neovascular AMD or disciform scarring. The visual prognosis of RAP lesions was conventionally thought to be poor, but subgroup analysis of the Verteporfin in Photodynamic Therapy (VIP) trial showed that the natural history is in fact quite variable, as in typical neovascular AMD, and the lesions responded well to photodynamic therapy (Scott and Bressler 2010). 
Y. Yonekawa and I.K. Kim

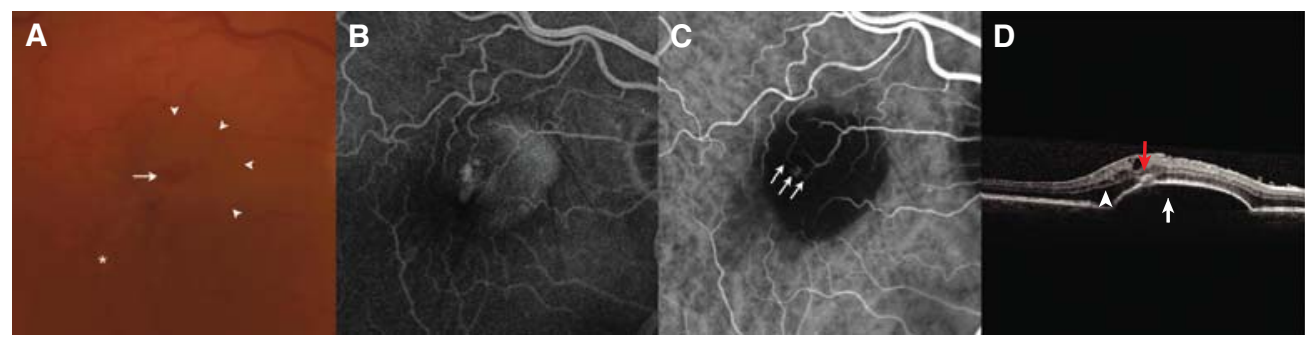

Figure 8. Retinal angiomatous proliferation (RAP). (A) Color fundus photograph showing focal intraretinal hemorrhage (arrow) and an underlying pigment epithelial detachment (PED) (arrowheads). There are also drusen (asterisk). (B) Fluorescein angiography shows a focal hyperfluorescence and the underlying PED. (C) Indocyanine green angiography reveals an anastomotic lesion connecting retinal vasculature (arrows). $(D)$ Spectral-domain optical coherence tomography also shows that there is intraretinal fluid (arrowhead) in addition to the PED (white arrow). A hyperreflective focus on the surface of the PED corresponds to the RAP lesion (red arrow).

\section{TREATMENT OF NONNEOVASCULAR AMD}

AREDS was a randomized, double-masked clinical trial, which examined the effect of antioxidant and zinc supplementation on progression of AMD. (AREDS Study Group 2000; AREDS Study Group 2001). It enrolled 3640 participants who were stratified into four categories of severity. Category 1: essentially no AMD, with total drusen area less than 5 small drusen $(<63 \mu \mathrm{m})$; Category 2: mild AMD with multiple small drusen or single/scattered intermediate drusen $(63-124 \mu \mathrm{m})$, and/or pigmentary changes; Category 3: at least one large druse $(\geq 125 \mu \mathrm{m})$ and/or extensive intermediate drusen and/or geographic atrophy not involving the central macula; Category 4: advanced AMD in the fellow nonstudy eye. Participants were randomized to one of four treatment arms: oral daily supplementation with (1) antioxidants (vitamin C $500 \mathrm{mg}$, vitamin E $400 \mathrm{IU}$, $\beta$-carotene $15 \mathrm{mg}$ ), (2) zinc (zinc oxide $80 \mathrm{mg}$ and copper $2 \mathrm{mg}$ ), (3) the combination of antioxidants and zinc, or (4) placebo.

Control patients in Category 2 had a 1.3\% probability of progressing to advanced AMD in 5 yr. Category 3 had 18\% likelihood, and Category 4 had $43 \%$. The largest risk reduction was seen in Category 3 and 4 participants who were randomized to take both antioxidants and zinc (odds radio 0.66 , or $34 \%$ odds reduction; $p=0.001)$. This group also had the largest reduction in loss of 15 letters or more with an odds ratio of $0.73(p=0.008)$, corresponding to a $27 \%$ risk reduction. Based on these findings, it was recommended that patients in Category 3 and 4 would benefit from antioxidant and zinc supplementation. Current and former heavy smokers were urged to take a regimen free of $\beta$-carotene, which has been shown by epidemiologic studies to increase the risk of lung cancer in smokers.

The AREDS investigators initiated AREDS 2 in 2006 (AREDS2 Study Group 2013). The goal was to determine whether adding omega3 fatty acids (docosahexanoic acid [DHA] and its precursor eicosapentanoic acid [EPA]) and/ or lutein and zeaxanthin to the original AREDS formulation would further reduce the risk of advanced AMD. 4203 participants with either bilateral large drusen or large drusen in one eye and advanced AMD in the fellow eye were randomized into four arms: (1) original AREDS, (2) AREDS + lutein $10 \mathrm{mg}+$ zeaxanthin $2 \mathrm{mg}$, (3) AREDS + DHA $350 \mathrm{mg}+$ EPA $650 \mathrm{mg}$, and (4) AREDS + DHA/EPA + lutein/zeaxanthin. In a secondary randomization, participants were randomized to the original AREDS formulation with or without $\beta$-carotene, and standard or lower doses of zinc.

The results (AREDS2 Study Group 2013) showed that there was no further benefit in adding DHA/EPA or lutein/zeaxanthin to the original AREDS formulation. However, it was found 
that participants who took the original AREDS formulation without $\beta$-carotene but with lutein and zeaxanthin and had slightly lower rates of progression to advanced AMD, compared to those taking the original formulation with $\beta$ carotene (hazard ratio $0.82 ; p=0.02$ ). Therefore it was suggested that lutein/zeaxanthin could be substituted for $\beta$-carotene.

\section{Treatments in Development}

The complement pathway has been implicated in the pathogenesis of AMD and many clinical trials are under way to investigate whether complement inhibitors can slow the progression of nonneovascular AMD. Studies of a systemically administered anti-C5 antibody, eculizumab, failed to show efficacy in reducing drusen volume or progression of geographic atrophy. (Garcia Filho et al. 2014; Yehoshua et al. 2014). A Phase II sham-controlled, randomized study that enrolled 129 patients with bilateral geographic atrophy, and showed that monthly intravitreal injections of lampalizumab (antifactor D, Roche/Genentech) resulted in a $20 \%$ reduction in the rate of growth geographic atrophy at 18 mo (Regillo 2013). Of note, patients positive for a specific complement factor I polymorphism ( $57 \%$ of the study participants) benefited from a $44 \%$ growth reduction. Many other trials of complement inhibitors are also in progress (Miller 2013).

Other potential therapeutic strategies in development include targeting inflammasomes, visual cycle modulation, and neuroprotection. Inflammasomes are multiprotein complexes that activate inflammatory cascades, and have been identified as potential targets for both nonneovascular (Tarallo et al. 2012) and neovascular (Doyle et al. 2012) AMD. Interrupting the photoreceptor light cycle to decrease the accumulation of A2E, a toxic component of lipofuscin, is another avenue under investigation. Early trials indicate that visual cycle modulators may have a role in slowing the progression of geographic atrophy (Kubota et al. 2012; Mata et al. 2013). Research in neuroprotection aims to identify agents that will interfere with cell death pathways and inhibit the loss of neural retina that is the ultimate cause of vision loss in AMD as well as many other disorders. (Trichonas et al. 2010; Wong et al. 2010; Zhang et al. 2011a; Miller 2013; Tsai 2013). Subretinal transplantation of stem cells is also being investigated as a means of regenerating RPE cells and eventually, perhaps photoreceptors as well (Schwartz et al. 2012).

\section{TREATMENT OF NEOVASCULAR AMD}

\section{Photocoagulation}

The Macular Photocoagulation Study (MPS) demonstrated the efficacy of argon photocoagulation for extrafoveal CNV (MPS Study Group 1982; MPS Study Group 1986). However, this treatment modality has been largely abandoned because of frequent recurrences and limited applicability.

\section{Macular Surgery}

Submacular surgery to directly remove neovascular membranes evolved in the 1990s as an alternative to observation or photocoagulation. The Submacular Surgery Trials showed that there was no benefit in visual outcomes in patients with subfoveal CNV treated with submacular surgery (Hawkins et al. 2004). However, treated lesions that were predominantly hemorrhagic lost less vision compared with observation (Bressler et al. 2004), although this did not translate into improved quality of life (Childs et al. 2004).

Macular translocation is a surgical procedure in which CNV is typically removed and the macula is displaced so that the fovea overlies normal RPE (Machemer and Steinhorst 1993; Ninomiya et al. 1996; de Juan et al. 1998; Lai et al. 2002; Mruthyunjaya et al. 2004). Limited macular translocation involves partially detaching the retina via injection of subretinal fluid and shifting the inferior retina downward with the help of a gas bubble to create a retinal fold. Another translocation technique involves $360^{\circ}$ peripheral retinectomy to fully detach and rotate the entire retina. Since the emergence of pharmacological therapies, surgical techniques 
are rarely used in management of neovascular AMD.

The current primary indication for surgical intervention in neovascular AMD is management of large submacular hemorrhages. Displacement of such hemorrhage is often attempted with vitrectomy and subretinal injection of tissue plasminogen activator and intravitreal gas (Hassan et al. 1999; Hattenbach et al. 2001; Haupert et al. 2001; Olivier et al. 2004; Singh et al. 2006). Successful pneumatic displacement with intravitreal gas injection, injections without vitrectomy and with or without tissue plasminogen activator, have also been reported (Ohji et al. 1998; Daneshvar et al. 1999; Ron et al. 2007; Mizutani et al. 2011).

\section{Photodynamic Therapy}

Photodynamic therapy (PDT) using verteporfin (Visudyne; Valeant Ophthalmics, Bridgewater, NJ) was approved by the United States Food and Drug Administration (FDA) for the treatment of neovascular AMD in 2000. PDT uses intravenously administered photosensitizing molecules that can be activated by photons in specific wavelengths, which allows photochemical damage by the generation of free radicals. An advantage over photocoagulation is the relative sparing of normal tissue, because only tissues that accumulate the photosensitizers are directly affected.

The Treatment of AMD with Photodynamic Therapy (TAP) trial was the phase III study that established the efficacy of PDT for neovascular AMD (TAP-Study-Group 1999). It randomized 609 participants with subfoveal neovascular AMD with a predominantly classic component, to verteporfin PDTor placebo. More eyes treated with PDT lost less than 15 letters of visual acuity at $12 \mathrm{mo}(61 \%$ vs. $46 \% ; p<0.001)$. Eyes with predominantly classic lesions benefited the most. The benefits were sustained at two (Bressler 2001) and three years (Blumenkranz et al. 2002).

The VIP study examined verteporfin PDT for the treatment of subfoveal occult-only lesions and classic lesions with good visual acuities (VIP Study Group 2001). Eyes treated with
PDT experienced less vision loss of 15 or more letters $(54 \%$ vs $67 \% ; p=0.023)$ at two years compared with placebo. The VIO trial also randomized patients with occult lesions to PDT or placebo, but showed only a trend favoring PDT that was not statistically significant (Kaiser 2009).

\section{Anti-VEGF Therapy}

\section{Pegaptanib}

Pegaptanib sodium (Macugen; Valeant Ophthalmics, Bridgewater, NJ) is a pegylated RNA aptamer that selectively binds $\mathrm{VEGF}_{165}$, which is thought to be one of the primary pathologic VEGF isoforms. Pegaptanib became the first anti-VEGF agent approved by the FDA for treatment of neovascular AMD based on the VISION studies (Gragoudas et al. 2004) which demonstrated that pegaptanib $0.3 \mathrm{mg}$ given intravitreally every $6 \mathrm{wk}$ resulted in 70\% of patients losing fewer than 15 letters of visual acuity, compared to $55 \%$ of controls ( $p<$ 0.001 ). However, use of pegaptanib has been largely replaced by the pan-VEGF-A inhibitors.

\section{Ranibizumab}

Ranibizumab (Lucentis; Genentech, South San Francisco, CA) is a humanized monoclonal Fab fragment that neutralizes all active isoforms of VEGF-A. Its efficacy was demonstrated in the ANCHOR (Brown et al. 2009) and MARINA (Rosenfeld et al. 2006) trials, and it was FDA approved for the treatment of neovascular AMD in 2006.

The ANCHOR study randomized 430 participants with predominantly classic CNV to monthly $0.3 \mathrm{mg}$ ranibizumab, $0.5 \mathrm{mg}$ ranibizumab, or verteporfin PDT (Brown et al. 2009). The primary outcome of loss of fewer than 15 letters at 12 mo was met $(94.3 \%, 96.4 \%$, and $64.3 \%$, respectively; $p<0.001)$ and sustained at $24 \mathrm{mo}$. Visual acuity improved by 15 letters or more in $35.7 \%, 40.3 \%$, and $5.6 \%$, respectively $(p<0.001)$, at $12 \mathrm{mo}$, and similarly at $24 \mathrm{mo}$. At $12 \mathrm{mo}$, the mean letters gained or lost were +8.5 , +11.3 , and -9.5 , respectively $(p<0.001)$, and this difference was comparable at 24 mo. 
The MARINA trial randomized 716 participants with minimally classic or occult $\mathrm{CNV}$ with evidence of recent progression to $0.3 \mathrm{mg}$ ranibizumab, $0.5 \mathrm{mg}$ ranibizumab, or sham injections (Rosenfeld et al. 2006). At $12 \mathrm{mo},<15$ letters were lost in $94.5 \%, 94.6 \%$, and $62.2 \%$ of patients, respectively $(p<0.001)$. Visual acuity improved by 15 or more letters in $24.8 \%, 33.8 \%$, and $5.0 \%$ of patients, respectively $(p<0.001)$. Mean letters gained or lost were $+6.5,+7.2$, and -10.4 , respectively $(p<0.001)$. The benefits were sustained at 24 mo.

\section{Bevacizumab}

Bevacizumab (Avastin; Genentech, South San Francisco, CA), a monoclonal anti-VEGF-A antibody, is the parent molecule of ranibizumab. It is FDA approved for the treatment of several systemic malignancies, but is used off-label as a cost-effective anti-VEGF agent for various ophthalmic conditions. The Comparison of AMD Treatment Trials (CATT) study was a federally funded, multicenter, noninferiority trial that randomized 1208 participants with neovascular AMD to receive ranibizumab or bevacizumab on either a monthly schedule or "as needed." (Martin et al. 2011, 2012). Monthly bevacizumab and monthly ranibizumab had similar efficacies, with a mean of 8.0 and 8.5 letters gained, respectively. The as-needed schedules were also comparable, with 5.9 and 6.8 letters gained, respectively. The difference between monthly and as-needed regimens did not reach statistical significance.

\section{Aflibercept}

Aflibercept (Eylea; Regeneron, Tarrytown, NY) is a recombinant fusion protein of the ligandbinding elements of VEGF receptors 1 and 2, which are fused to the Fc portion of human IgG1. It blocks all VEGF-A isoforms, VEGF-B and placental growth factor (Browning et al. 2012; Stewart 2012). The benefit of aflibercept over previous agents is its demonstrated efficacy when given on a less frequent bimonthly injection schedule (Papadopoulos et al. 2012). Aflibercept was FDA approved in 2011 after the results of the VIEW 1 and VIEW 2 studies, which were two parallel phase III trials that randomized 2419 patients to $0.5 \mathrm{mg}$ monthly aflibercept, $2.0 \mathrm{mg}$ monthly aflibercept, $2.0 \mathrm{mg}$ aflibercept every 2 mo after three initial monthly doses, or monthly $0.5 \mathrm{mg}$ ranibizumab (Heier et al. 2012). All aflibercept groups were comparable to monthly ranibizumab for the primary endpoint (proportion of patients losing $<15$ letters at $1 \mathrm{yr}$ ). The letters gained and anatomic measures as seen on OCT were also comparable.

\section{Combination Therapy}

The role of PDT in treating typical neovascular AMD has become limited to refractory cases given the superior results obtained with antiVEGF therapy. Studies investigating combination PDT and anti-VEGF therapy for AMD did not show benefit with respect to visual acuity or significant reduction in number of injections (Kaiser et al. 2012; Larsen et al. 2012).

PDT, however, still plays an important role in the treatment of PCV (Kurashige et al. 2008; Kang et al. 2013; Yamashita et al. 2013). AntiVEGF agents can decrease the exudation associated with PCV to improve visual acuity, but often do not close the polypoidal vascular abnormalities (Gomi et al. 2008; Koizumi et al. 2011); the local photochemical damage of PDT can directly close these channels (Koh et al. 2012). Combining PDTwith anti-VEGF agents appears to be an effective approach (Kim and Yu 2011; Koh et al. 2012; Lee et al. 2012b; Tomita et al. 2012). The EVEREST study randomized 61 patients with PCV to verteporfin PDT, ranibizumab $0.5 \mathrm{mg}$, or the combination, and showed that PDT with ranibizumab or PDT alone was superior to ranibizumab monotherapy in achieving polyp regression at 6 mo $(p<0.01)$ (Koh et al. 2012).

Despite the success of current pharmacotherapies for neovascular AMD, better visual results and more durable therapies remain goals to be achieved. Strategies under investigation include inhibition of platelet-derived growth factor (Boyer 2013), and other mechanisms of VEGF blockade including anti-VEGF gene therapy. (Lukason et al. 2011; Zhang et al. 2011b; Campochiaro et al. 2013). 


\section{CONCLUDING REMARKS}

Many recent advances in ophthalmology have been in the arena of AMD. From genetic studies to new imaging technology, breakthroughs in treatment, and gains in the fundamental understanding of its pathophysiology, the strides made in AMD research have prevented blindness in millions of individuals. However, better and further-reaching treatments are needed. Directions for ongoing and future research that will help achieve such treatments include more precise phenotyping of AMD utilizing modern imaging capabilities combined with genotyping, a deeper understanding of AMD pathophysiology, improved disease models, further insight into pharmacogenomic interactions, and new drug delivery technology.

\section{REFERENCES}

AREDS Study Group. 2000. Risk factors associated with age-related macular degeneration. A case-control study in the age-related eye disease study: Age-Related Eye Disease Study Report Number 3. Ophthalmology 107: 22242232.

AREDS Study Group. 2001. A randomized, placebo-controlled, clinical trial of high-dose supplementation with vitamins $C$ and $E, \beta$ carotene, and zinc for age-related macular degeneration and vision loss: AREDS report no. 8. Arch Ophthalmol 119: 1417-1436.

AREDS2 Study Group. 2013. Lutein + zeaxanthin and omega- 3 fatty acids for age-related macular degeneration: the Age-Related Eye Disease Study 2 (AREDS2) randomized clinical trial. JAMA 309: 2005-2015.

Arnold JJ, Sarks SH, Killingsworth MC, Sarks JP. 1995. Reticular pseudodrusen. A risk factor in age-related maculopathy. Retina 15: 183-191.

Blumenkranz MS, Bressler NM, Bressler SB, Donati G, Fish GE, Haynes LA, Lewis H, Miller JW, Mones JM, Potter MJ, et al. 2002. Verteporfin therapy for subfoveal choroidal neovascularization in age-related macular degeneration: Three-year results of an open-label extension of 2 randomized clinical trials-TAP Report no. 5. Arch Ophthalmol 120: 1307-1314.

Boyer D. 2013. A phase $2 \mathrm{~b}$ study of Fovista ${ }^{\mathrm{TM}}$, a platelet derived growth factor (PDGF) inhibitor in combination with a vascular endothelial growth factor (VEGF) inhibitor for neovascular age-related macular degeneration (AMD). Association for Research in Vision and Ophthalmology Annual Meeting, Abstract 2175. Seattle, May $5-9$.

Bressler NM, TAP Study Group. 2001. Photodynamic therapy of subfoveal choroidal neovascularization in age-related macular degeneration with verteporfin: Two-year results of 2 randomized clinical trials-tap report 2. Arch Ophthalmol 119: 198-207.
Bressler NM, Silva JC, Bressler SB, Fine SL, Green WR. 1994. Clinicopathologic correlation of drusen and retinal pigment epithelial abnormalities in age-related macular degeneration. Retina 14: 130-142.

Bressler NM, Bressler SB, Childs AL, Haller JA, Hawkins BS, Lewis H, MacCumber MW, Marsh MJ, Redford M, Sternberg P Jr, et al. 2004. Surgery for hemorrhagic choroidal neovascular lesions of age-related macular degeneration: Ophthalmic findings: SST report no. 13. Ophthalmology 111: 1993-2006.

Brown DM, Michels M, Kaiser PK, Heier JS, Sy JP, Ianchulev T. 2009. Ranibizumab versus verteporfin photodynamic therapy for neovascular age-related macular degeneration: Two-year results of the ANCHOR study. Ophthalmology 116: 57-65, e55.

Browning DJ, Kaiser PK, Rosenfeld PJ, Stewart MW. 2012. Aflibercept for age-related macular degeneration: A game-changer or quiet addition? Am J Ophthalmol 154: 222-226.

Campochiaro PA, Channa R, Berger BB, Heier JS, Brown DM, Fiedler U, Hepp J, Stumpp MT. 2013. Treatment of diabetic macular edema with a designed ankyrin repeat protein that binds vascular endothelial growth factor: A phase I/II study. Am J Ophthalmol 155: 697-704, 704 e691-e692.

Childs AL, Bressler NM, Bass EB, Hawkins BS, Mangione CM, Marsh MJ, Miskala PH. 2004. Surgery for hemorrhagic choroidal neovascular lesions of age-related macular degeneration: Quality-of-life findings: SST report no. 14. Ophthalmology 111: 2007-2014.

Christen WG, Glynn RJ, Manson JE, Ajani UA, Buring JE. 1996. A prospective study of cigarette smoking and risk of age-related macular degeneration in men. JAMA 276: 1147-1151.

Cohen SY, Dubois L, Tadayoni R, Delahaye-Mazza C, Debibie C, Quentel G. 2007. Prevalence of reticular pseudodrusen in age-related macular degeneration with newly diagnosed choroidal neovascularisation. Br J Ophthalmol 91: 354-359.

Cukras C, Agron E, Klein ML, Ferris FL 3rd, Chew EY, Gensler G, Wong WT. 2010. Natural history of drusenoid pigment epithelial detachment in age-related macular degeneration: Age-Related Eye Disease Study Report No. 28. Ophthalmology 117: 489-499.

Curcio CA, Millican CL, Allen KA, Kalina RE. 1993. Aging of the human photoreceptor mosaic: Evidence for selective vulnerability of rods in central retina. Invest Ophthalmol Vis Sci 34: 3278-3296.

Daneshvar H, Kertes PJ, Leonard BC, Peyman GA. 1999. Management of submacular hemorrhage with intravitreal sulfur hexafluoride: A pilot study. Can J Ophthalmol 34: $385-388$.

de Juan E Jr, Loewenstein A, Bressler NM, Alexander J. 1998. Translocation of the retina for management of subfoveal choroidal neovascularization II: A preliminary report in humans. Am J Ophthalmol 125: 635-646.

Do DV, Gower EW, Cassard SD, Boyer D, Bressler NM, Bressler SB, Heier JS, Jefferys JL, Singerman LJ, Solomon SD. 2012. Detection of new-onset choroidal neovascularization using optical coherence tomography: The AMD DOC Study. Ophthalmology 119: 771-778. 
Doyle SL, Campbell M, Ozaki E, Salomon RG, Mori A, Kenna PF, Farrar GJ, Kiang AS, Humphries MM, Lavelle EC, et al. 2012. NLRP3 has a protective role in age-related macular degeneration through the induction of IL- 18 by drusen components. Nat Med 18: 791-798.

Eye-Disease-Case-Control-Study-Group. 1992. Risk factors for neovascular age-related macular degeneration. Arch Ophthalmol 110: 1701-1708.

Feehan M, Hartman J, Durante R, Morrison MA, Miller JW, Kim IK, DeAngelis MM. 2011. Identifying subtypes of patients with neovascular age-related macular degeneration by genotypic and cardiovascular risk characteristics. BMC Med Genet 12: 83 .

Feeney-Burns L, Berman ER, Rothman H. 1980. Lipofuscin of human retinal pigment epithelium. Am J Ophthalmol 90: 783-791.

Feeney-Burns L, Burns RP, Gao CL. 1990. Age-related macular changes in humans over 90 years old. Am J Ophthalmol 109: 265-278.

Ferris FL III, Fine SL, Hyman L. 1984. Age-related macular degeneration and blindness due to neovascular maculopathy. Arch Ophthalmol 102: 1640-1642.

Freund KB, Ho IV, Barbazetto IA, Koizumi H, Laud K, Ferrara D, Matsumoto Y, Sorenson JA, Yannuzzi L. 2008. Type 3 neovascularization: The expanded spectrum of retinal angiomatous proliferation. Retina 28: 201-211.

Friedman DS, O'Colmain BJ, Munoz B, Tomany SC, McCarty C, de Jong PT, Nemesure B, Mitchell P, Kempen J. 2004. Prevalence of age-related macular degeneration in the United States. Arch Ophthalmol 122: 564-572.

Garcia Filho CA, Yehoshua Z, Gregori G, Nunes RP, Penha FM, Moshfeghi AA, Zhang K, Feuer W, Rosenfeld PJ. 2014. Change in drusen volume as a novel clinical trial endpoint for the study of complement inhibition in agerelated macular degeneration. Ophthalmic Surg Lasers Imaging Retina 45: 18-31.

Gass JD, Agarwal A, Lavina AM, Tawansy KA. 2003. Focal inner retinal hemorrhages in patients with drusen: An early sign of occult choroidal neovascularization and chorioretinal anastomosis. Retina 23: 741-751.

Goldberg J, Flowerdew G, Smith E, Brody JA, Tso MO. 1988. Factors associated with age-related macular degeneration. An analysis of data from the first National Health and Nutrition Examination Survey. Am J Epidemiol 128: $700-710$.

Gomi F, Sawa M, Sakaguchi H, Tsujikawa M, Oshima Y, Kamei M, Tano Y. 2008. Efficacy of intravitreal bevacizumab for polypoidal choroidal vasculopathy. Br J Ophthalmol 92: 70-73.

Gragoudas ES, Adamis AP, Cunningham ET Jr, Feinsod M, Guyer DR. 2004. Pegaptanib for neovascular age-related macular degeneration. $N$ Engl J Med 351: 2805-2816.

Hartnett ME, Weiter JJ, Garsd A, Jalkh AE. 1992. Classification of retinal pigment epithelial detachments associated with drusen. Graefes Arch Clin Exp Ophthalmol 230: $11-19$.

Hassan AS, Johnson MW, Schneiderman TE, Regillo CD, Tornambe PE, Poliner LS, Blodi BA, Elner SG. 1999. Management of submacular hemorrhage with intravitreous tissue plasminogen activator injection and pneumatic displacement. Ophthalmology 106: 1900-1907.
Hattenbach LO, Klais C, Koch FH, Gumbel HO. 2001. Intravitreous injection of tissue plasminogen activator and gas in the treatment of submacular hemorrhage under various conditions. Ophthalmology 108: 1485-1492.

Haupert CL, McCuen BW II, Jaffe GJ, Steuer ER, Cox TA, Toth CA, Fekrat S, Postel EA. 2001. Pars plana vitrectomy, subretinal injection of tissue plasminogen activator, and fluid-gas exchange for displacement of thick submacular hemorrhage in age-related macular degeneration. Am J Ophthalmol 131: 208-215.

Hawkins BS, Bressler NM, Miskala PH, Bressler SB, Holekamp NM, Marsh MJ, Redford M, Schwartz SD, Sternberg P Jr, Thomas MA, et al. 2004. Surgery for subfoveal choroidal neovascularization in age-related macular degeneration: Ophthalmic findings: SST report no. 11. Ophthalmology 111: 1967-1980.

Heier JS, Brown DM, Chong V, Korobelnik J-F, Kaiser PK, Nguyen QD, Kirchhof B, Ho A, Ogura Y, Yancopoulos $\mathrm{GD}$, et al. 2012. Intravitreal aflibercept (VEGF Trap-Eye) in wet age-related macular degeneration. Ophthalmology 119: $2537-2548$.

Holz FG, Bellman C, Staudt S, Schutt F, Volcker HE. 2001. Fundus autofluorescence and development of geographic atrophy in age-related macular degeneration. Invest Ophthalmol Vis Sci 42: 1051-1056.

Hyman L, Schachat AP, He Q, Leske MC. 2000. Hypertension, cardiovascular disease, and age-related macular degeneration. Age-Related Macular Degeneration Risk Factors Study Group. Arch Ophthalmol 118: 351-358.

Imamura Y, Engelbert M, Iida T, Freund KB, Yannuzzi LA. 2010. Polypoidal choroidal vasculopathy: A review. Surv Ophthalmol 55: 501-515.

Kaiser PK. 2009. Verteporfin PDT for subfoveal occult CNV in AMD: Two-year results of a randomized trial. Curr Med Res Opin 25: 1853-1860.

Kaiser PK, Boyer DS, Cruess AF, Slakter JS, Pilz S, Weisberger A. 2012. Verteporfin plus ranibizumab for choroidal neovascularization in age-related macular degeneration: Twelve-month results of the DENALI study. Ophthalmology 119: 1001-1010.

Kang HM, Kim YM, Koh HJ. 2013. Five-year follow-up results of photodynamic therapy for polypoidal choroidal vasculopathy. Am J Ophthalmol 155: 438-447, e431.

Kawasaki R, Yasuda M, Song SJ, Chen SJ, Jonas JB, Wang JJ, Mitchell P, Wong TY. 2010. The prevalence of age-related macular degeneration in Asians: A systematic review and meta-analysis. Ophthalmology 117: 921-927.

Khurana RN, Dupas B, Bressler NM. 2010. Agreement of time-domain and spectral-domain optical coherence tomography with fluorescein leakage from choroidal neovascularization. Ophthalmology 117: 1376-1380.

Kim SJ, Yu HG. 2011. Efficacy of combined photodynamic therapy and intravitreal bevacizumab injection versus photodynamic therapy alone in polypoidal choroidal vasculopathy. Retina 31: 1827-1834.

Klein R, Klein BE, Linton KL. 1992. Prevalence of age-related maculopathy. The Beaver Dam Eye Study. Ophthalmology 99: 933-943.

Klein R, Klein BE, Franke T. 1993. The relationship of cardiovascular disease and its risk factors to age-related maculopathy. The Beaver Dam Eye Study. Ophthalmology 100: $406-414$ 
Klein R, Klein BE, Tomany SC, Cruickshanks KJ. 2003. The association of cardiovascular disease with the long-term incidence of age-related maculopathy: The Beaver Dam Eye Study. Ophthalmology 110: 1273-1280.

Klein ML, Ferris FL III, Armstrong J, Hwang TS, Chew EY, Bressler SB, Chandra SR. 2008a. Retinal precursors and the development of geographic atrophy in age-related macular degeneration. Ophthalmology 115: 1026-1031.

Klein R, Meuer SM, Knudtson MD, Iyengar SK, Klein BE. 2008b. The epidemiology of retinal reticular drusen. Am J Ophthalmol 145: 317-326.

Klein R, Cruickshanks KJ, Myers CE, Sivakumaran TA, Iyengar SK, Meuer SM, Schubert CR, Gangnon RE, Klein BE. 2013. The relationship of atherosclerosis to the 10-year cumulative incidence of age-related macular degeneration: The Beaver Dam studies. Ophthalmology 120: 1012-1019.

Koh A, Lee WK, Chen LJ, Chen SJ, Hashad Y, Kim H, Lai TY, Pilz S, Ruamviboonsuk P, Tokaji E, et al. 2012. EVEREST study: Efficacy and safety of verteporfin photodynamic therapy in combination with ranibizumab or alone versus ranibizumab monotherapy in patients with symptomatic macular polypoidal choroidal vasculopathy. Retina 32: $1453-1464$.

Koizumi H, Yamagishi T, Yamazaki T, Kinoshita S. 2011. Predictive factors of resolved retinal fluid after intravitreal ranibizumab for polypoidal choroidal vasculopathy. $\mathrm{BrJ}$ Ophthalmol 95: 1555-1559.

Kubota R, Boman NL, David R, Mallikaarjun S, Patil S, Birch D. 2012. Safety and effect on rod function of ACU-4429, a novel small-molecule visual cycle modulator. Retina 32: $183-188$.

Kurashige Y, Otani A, Sasahara M, Yodoi Y, Tamura H, Tsujikawa A, Yoshimura N. 2008. Two-year results of photodynamic therapy for polypoidal choroidal vasculopathy. Am J Ophthalmol 146: 513-519.

Laatikainen L, Larinkari J. 1977. Capillary-free area of the fovea with advancing age. Invest Ophthalmol Vis Sci 16: 1154-1157.

Lai JC, Lapolice DJ, Stinnett SS, Meyer CH, Arieu LM, Keller MA, Toth CA. 2002. Visual outcomes following macular translocation with 360-degree peripheral retinectomy. Arch Ophthalmol 120: 1317-1324.

Larsen M, Schmidt-Erfurth U, Lanzetta P, Wolf S, Simader C, Tokaji E, Pilz S, Weisberger A. 2012. Verteporfin plus ranibizumab for choroidal neovascularization in age-related macular degeneration: Twelve-month MONT BLANC study results. Ophthalmology 119: 992-1000.

Lee SY, Stetson PF, Ruiz-Garcia H, Heussen FM, Sadda SR. 2012a. Automated characterization of pigment epithelial detachment by optical coherence tomography. Invest Ophthalmol Vis Sci 53: 164-170.

Lee YA, Yang CH, Yang CM, Ho TC, Lin CP, Huang JS, Chen MS. 2012b. Photodynamic therapy with or without intravitreal bevacizumab for polypoidal choroidal vasculopathy: Two years of follow-up. Am J Ophthalmol 154: 872-880, e872.

Lukason M, DuFresne E, Rubin H, Pechan P, Li Q, Kim I, Kiss S, Flaxel C, Collins M, Miller J, et al. 2011. Inhibition of choroidal neovascularization in a nonhuman primate model by intravitreal administration of an AAV2 vector expressing a novel anti-VEGF molecule. Mol Ther 19: 260-265.

Machemer R, Steinhorst UH. 1993. Retinal separation, retinotomy, and macular relocation: II. A surgical approach for age-related macular degeneration? Graefes Arch Clin Exp Ophthalmol 231: 635-641.

Malamos P, Sacu S, Georgopoulos M, Kiss C, Pruente C, Schmidt-Erfurth U. 2009. Correlation of high-definition optical coherence tomography and fluorescein angiography imaging in neovascular macular degeneration. Invest Ophthalmol Vis Sci 50: 4926-4933.

Martin DF, Maguire MG, Ying GS, Grunwald JE, Fine SL, Jaffe GJ. 2011. Ranibizumab and bevacizumab for neovascular age-related macular degeneration. $N$ Engl J Med 364: 1897-1908.

Martin DF, Maguire MG, Fine SL, Ying GS, Jaffe GJ, Grunwald JE, Toth C, Redford M, Ferris FL III. 2012. Ranibizumab and bevacizumab for treatment of neovascular age-related macular degeneration: Two-year results. Ophthalmology 119: 1388-1398.

Maruko I, Iida T, Saito M, Nagayama D, Saito K. 2007. Clinical characteristics of exudative age-related macular degeneration in Japanese patients. Am J Ophthalmol 144: $15-22$

Mata NL, Lichter JB, Vogel R, Han Y, Bui TV, Singerman LJ. 2013. Investigation of oral fenretinide for treatment of geographic atrophy in age-related macular degeneration. Retina 33: 498-507.

Miller JW. 2013. Age-related macular degeneration revisited-Piecing the puzzle: The LXIX Edward Jackson memorial lecture. Am J Ophthalmol 155: 1-35, e13.

Mimoun G, Soubrane G, Coscas G. 1990. Macular drusen. I Fr Ophtalmol 13: 511-530.

Mizutani T, Yasukawa T, Ito Y, Takase A, Hirano Y, Yoshida M, Ogura Y. 2011. Pneumatic displacement of submacular hemorrhage with or without tissue plasminogen activator. Graefes Arch Clin Exp Ophthalmol 249: 1153 1157.

MPS Study Group. 1982. Argon laser photocoagulation for senile macular degeneration. Results of a randomized clinical trial. Arch Ophthalmol 100: 912-918.

MPS Study Group. 1986. Argon laser photocoagulation for neovascular maculopathy. Three-year results from randomized clinical trials. Arch Ophthalmol 104: 694-701.

Mruthyunjaya P, Stinnett SS, Toth CA. 2004. Change in visual function after macular translocation with $360^{\circ}$ retinectomy for neovascular age-related macular degeneration. Ophthalmology 111: 1715-1724.

Ninomiya Y, Lewis JM, Hasegawa T, Tano Y. 1996. Retinotomy and foveal translocation for surgical management of subfoveal choroidal neovascular membranes. Am J Ophthalmol 122: 613-621.

Ohji M, Saito Y, Hayashi A, Lewis JM, Tano Y. 1998. Pneumatic displacement of subretinal hemorrhage without tissue plasminogen activator. Arch Ophthalmol 116: $1326-1332$.

Olivier S, Chow DR, Packo KH, MacCumber MW, Awh CC. 2004. Subretinal recombinant tissue plasminogen activator injection and pneumatic displacement of thick submacular hemorrhage in age-related macular degeneration. Ophthalmology 111: 1201-1208. 
Panda-Jonas S, Jonas JB, Jakobczyk-Zmija M. 1996. Retinal pigment epithelial cell count, distribution, and correlations in normal human eyes. Am J Ophthalmol 121: 181189.

Papadopoulos N, Martin J, Ruan Q, Rafique A, Rosconi MP, Shi E, Pyles EA, Yancopoulos GD, Stahl N, Wiegand SJ. 2012. Binding and neutralization of vascular endothelial growth factor (VEGF) and related ligands by VEGF Trap, ranibizumab and bevacizumab. Angiogenesis 15: 171185.

Pumariega NM, Smith RT, Sohrab MA, Letien V, Souied EH. 2011. A prospective study of reticular macular disease. Ophthalmology 118: 1619-1625.

Regillo CD. 2013. Lampalizumab (anti-factor D) in patients with geography atrophy: The MAHALO phase 2 results. Annual Meeting of the American Academy of Ophthalmology, New Orleans, November 16-19.

Ron Y, Ehrlich R, Axer-Siegel R, Rosenblatt I, Weinberger D. 2007. Pneumatic displacement of submacular hemorrhage due to age-related macular degeneration. Ophthalmologica 221: 57-61.

Rosenfeld PJ, Brown DM, Heier JS, Boyer DS, Kaiser PK, Chung CY, Kim RY. 2006. Ranibizumab for neovascular age-related macular degeneration. $N$ Engl J Med 355: 1419-1431.

Sarks SH. 1976. Ageing and degeneration in the macular region: a clinico-pathological study. $\mathrm{Br} J$ Ophthalmol 60: $324-341$.

Sarks SH, Van Driel D, Maxwell L, Killingsworth M. 1980. Softening of drusen and subretinal neovascularization. Trans Ophthalmol Soc U K 100: 414-422.

Sarks JP, Sarks SH, Killingsworth MC. 1988. Evolution of geographic atrophy of the retinal pigment epithelium. Eye (Lond) 2 (Pt 5): 552-577.

Sarks S, Cherepanoff S, Killingsworth M, Sarks J. 2007. Relationship of Basal laminar deposit and membranous debris to the clinical presentation of early age-related macular degeneration. Invest Ophthalmol Vis Sci 48: 968-977.

Sayanagi K, Sharma S, Yamamoto T, Kaiser PK. 2009. Comparison of spectral-domain versus time-domain optical coherence tomography in management of age-related macular degeneration with ranibizumab. Ophthalmology 116: $947-955$.

Schmitz-Valckenberg S, Bindewald-Wittich A, DolarSzczasny J, Dreyhaupt J, Wolf S, Scholl HP, Holz FG. 2006. Correlation between the area of increased autofluorescence surrounding geographic atrophy and disease progression in patients with AMD. Invest Ophthalmol Vis Sci 47: 2648-2654.

Schmitz-Valckenberg S, Fleckenstein M, Scholl HP, Holz FG. 2009. Fundus autofluorescence and progression of agerelated macular degeneration. Surv Ophthalmol 54: $96-$ 117.

Schmitz-Valckenberg S, Steinberg JS, Fleckenstein M, Visvalingam S, Brinkmann CK, Holz FG. 2010. Combined confocal scanning laser ophthalmoscopy and spectraldomain optical coherence tomography imaging of reticular drusen associated with age-related macular degeneration. Ophthalmology 117: 1169-1176.

Schwartz SD, Hubschman JP, Heilwell G, Franco-Cardenas V, Pan CK, Ostrick RM, Mickunas E, Gay R, Klimanskaya
I, Lanza R. 2012. Embryonic stem cell trials for macular degeneration: a preliminary report. Lancet 379: 713-720.

Scott AW, Bressler SB. 2010. Retinal angiomatous proliferation or retinal anastomosis to the lesion. Eye (Lond) 24: 491-496.

Seddon JM, Willett WC, Speizer FE, Hankinson SE. 1996. A prospective study of cigarette smoking and age-related macular degeneration in women. JAMA 276: 1141-1146.

Singh RP, Patel C, Sears JE. 2006. Management of subretinal macular haemorrhage by direct administration of tissue plasminogen activator. Br J Ophthalmol 90: 429-431.

Sommer A, Tielsch JM, Katz J, Quigley HA, Gottsch JD, Javitt JC, Martone JF, Royall RM, Witt KA, Ezrine S. 1991. Racial differences in the cause-specific prevalence of blindness in East Baltimore. N Engl J Med 325: 1412-1417.

Sperduto RD, Hiller R. 1986. Systemic hypertension and age-related maculopathy in the Framingham Study. Arch Ophthalmol 104: 216-219.

Stewart MW. 2012. Aflibercept (VEGF Trap-eye): The newest anti-VEGF drug. Br J Ophthalmol 96: 1157-1158.

TAP Study Group. 1999. Photodynamic therapy of subfoveal choroidal neovascularization in age-related macular degeneration with verteporfin: One-year results of 2 randomized clinical trials-TAP report. Arch Ophthalmol 117: 1329-1345.

Tarallo V, Hirano Y, Gelfand BD, Dridi S, Kerur N, Kim Y, Cho WG, Kaneko H, Fowler BJ, Bogdanovich S, et al. 2012. DICER1 loss and $A l u$ RNA induce age-related macular degeneration via the NLRP3 inflammasome and MyD88. Cell 149: 847-859.

Tomita K, Tsujikawa A, Yamashiro K, Ooto S, Tamura H, Otani A, Nakayama Y, Yoshimura N. 2012. Treatment of polypoidal choroidal vasculopathy with photodynamic therapy combined with intravitreal injections of ranibizumab. Am J Ophthalmol 153: 68-80, e61.

Trichonas G, Murakami Y, Thanos A, Morizane Y, Kayama M, Debouck CM, Hisatomi T, Miller JW, Vavvas DG. 2010. Receptor interacting protein kinases mediate retinal detachment-induced photoreceptor necrosis and compensate for inhibition of apoptosis. Proc Natl Acad Sci 107: 21695-21700.

Tsai JC. 2013. Canadian Journal of Ophthalmology Lecture: Translational research advances in glaucoma neuroprotection. Can J Ophthalmol 48: 141-145.

van Leeuwen R, Ikram MK, Vingerling JR, Witteman JC, Hofman A, de Jong PT. 2003. Blood pressure, atherosclerosis, and the incidence of age-related maculopathy: The Rotterdam Study. Invest Ophthalmol Vis Sci 44: 3771-3777.

Varma R, Fraser-Bell S, Tan S, Klein R, Azen SP. 2004. Prevalence of age-related macular degeneration in Latinos: the Los Angeles Latino eye study. Ophthalmology 111: $1288-1297$.

Vinding T. 1995. Age-related macular degeneration. An epidemiological study of 1000 elderly individuals. With reference to prevalence, funduscopic findings, visual impairment and risk factors. Acta Ophthalmol Scand Suppl: $1-32$.

Vingerling JR, Dielemans I, Bots ML, Hofman A, Grobbee DE, de Jong PT. 1995. Age-related macular degeneration is associated with atherosclerosis. The Rotterdam Study. Am J Epidemiol 142: 404-409. 
Y. Yonekawa and I.K. Kim

VIP Study Group. 2001. Verteporfin therapy of subfoveal choroidal neovascularization in age-related macular degeneration: Two-year results of a randomized clinical trial including lesions with occult with no classic choroidal neovascularization-Verteporfin in photodynamic therapy report 2. Am J Ophthalmol 131: 541-560.

WHO. 2013. Prevention of blindness and visual impairment; priority eye diseases (http://www.who.int/ blindness/causes/priority/en/index7.html).

Wolff B, Matet A, Vasseur V, Sahel JA, Mauget-Faysse M. 2012. En face OCT imaging for the diagnosis of outer retinal tubulations in age-related macular degeneration. $J$ Ophthalmol 2012: 542417.

Wong WT, Kam W, Cunningham D, Harrington M, Hammel K, Meyerle CB, Cukras C, Chew EY, Sadda SR, Ferris FL. 2010. Treatment of geographic atrophy by the topical administration of OT-551: Results of a phase II clinical trial. Invest Ophthalmol Vis Sci 51: 6131-6139.

Yamashita A, Shiraga F, Shiragami C, Shirakata Y, Fujiwara A. 2013. Two-year results of reduced-fluence photodynamic therapy for polypoidal choroidal vasculopathy. Am J Ophthalmol 155: 96-102, e101.

Yannuzzi LA, Negrao S, Iida T, Carvalho C, Rodriguez-Coleman H, Slakter J, Freund KB, Sorenson J, Orlock D, Borodoker N. 2001. Retinal angiomatous proliferation in age-related macular degeneration. Retina 21: 416-434.

Yehoshua Z, de Amorim Garcia Filho CA, Nunes RP, Gregori G, Penha FM, Moshfeghi AA, Zhang K, Sadda S, Feuer W,
Rosenfeld PJ. 2014. Systemic complement inhibition with eculizumab for geographic atrophy in age-related macular degeneration: The COMPLETE study. Ophthalmology 121: 693-701.

Yonekawa Y. 2013. Aflibercept for the treatment of refractory polypoidal choroidal vasculopathy. Can J Ophthalmol 48: e59-e60.

Zarbin MA. 2004. Current concepts in the pathogenesis of age-related macular degeneration. Arch Ophthalmol 122: 598-614.

Zhang K, Hopkins JJ, Heier JS, Birch DG, Halperin LS, Albini TA, Brown DM, Jaffe GJ, Tao W, Williams GA. 2011a. Ciliary neurotrophic factor delivered by encapsulated cell intraocular implants for treatment of geographic atrophy in age-related macular degeneration. Proc Natl Acad Sci 108: 6241-6245.

Zhang M, Zhang J, Yan M, Luo D, Zhu W, Kaiser PK, Yu DC. 2011 b. A phase 1 study of KH902, a vascular endothelial growth factor receptor decoy, for exudative age-related macular degeneration. Ophthalmology 118: 672-678.

Zweifel SA, Engelbert M, Laud K, Margolis R, Spaide RF Freund KB. 2009. Outer retinal tubulation: A novel optical coherence tomography finding. Arch Ophthalmol 127: 1596-1602.

Zweifel SA, Imamura Y, Spaide TC, Fujiwara T, Spaide RF. 2010. Prevalence and significance of subretinal drusenoid deposits (reticular pseudodrusen) in age-related macular degeneration. Ophthalmology 117: 1775-1781. 


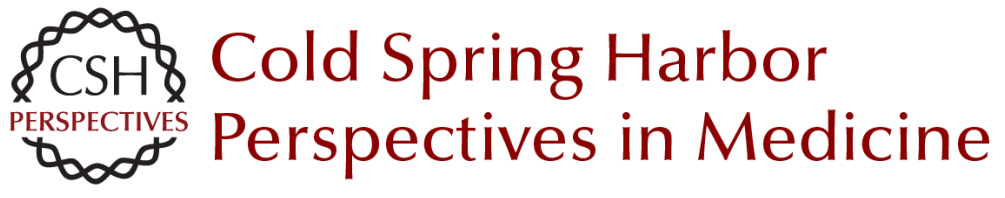

\title{
Clinical Characteristics and Current Treatment of Age-Related Macular Degeneration
}

\author{
Yoshihiro Yonekawa and Ivana K. Kim \\ Cold Spring Harb Perspect Med 2015; doi: 10.1101/cshperspect.a017178 originally published online \\ October 3, 2014
}

Subject Collection Retinal Disorders: Genetic Approaches to Diagnosis and Treatment

Trial by "Firsts": Clinical Trial Design and Regulatory Considerations in the Development and Approval of the First AAV Gene Therapy

Product in the United States

Kathleen Z. Reape and Katherine A. High

Immunology of Retinitis Pigmentosa and Gene Therapy-Associated Uveitis

Paul Yang, Debarshi Mustafi and Kathryn L. Pepple

Developing New Vectors for Retinal Gene Therapy Emilia A. Zin, Bilge E. Ozturk, Deniz Dalkara, et al.

Beyond the NEI-VFQ: Recent Experience in the Development and Utilization of Patient-Reported Outcomes for Inherited Retinal Diseases

Todd Durham, Judit Banhazi, Francesco Patalano, et al.

Electronic Retinal Prostheses

Daniel Palanker

Alternative RNA Splicing in the Retina: Insights and Perspectives

Casey J. Keuthan, Sadik Karma and Donald J. Zack

X-Linked Retinoschisis

Cristy A. Ku, Lisa W. Wei and Paul A. Sieving

A Systematic Review of Optogenetic Vision Restoration: History, Challenges, and New Inventions from Bench to Bedside

Antonia Stefanov and John G. Flannery
Lessons Learned from the Development of the

First FDA-Approved Gene Therapy Drug, Voretigene Neparvovec-rzyl Jean Bennett and Albert M. Maguire

Therapeutic Gene Editing in Inherited Retinal Disorders Jinjie Ling, Laura A. Jenny, Ashley Zhou, et al.

Cell-Based Therapies: Strategies for Regeneration Marina Pavlou and Thomas A. Reh

The Importance of Natural History Studies in Inherited Retinal Diseases Allison Ayala, Janet Cheetham, Todd Durham, et al.

\section{Photoreceptor Cell Replacement Using \\ Pluripotent Stem Cells: Current Knowledge and \\ Remaining Questions}

Christelle Monville, Olivier Goureau and Karim Ben M'Barek

iPSC-RPE in Retinal Degeneration: Recent

Advancements and Future Perspectives

Tadao Maeda and Masayo Takahashi

Retinal Degeneration Animal Models in Bardet-

Biedl Syndrome and Related Ciliopathies

Clarisse Delvallée and Hélène Dollfus

Mobility Testing and Other Performance-Based

Assessments of Functional Vision in Patients with Inherited Retinal Disease

Daniel Chung, Colas Authié and Laure Blouin

For additional articles in this collection, see http://perspectivesinmedicine.cshlp.org/cgi/collection/ 
For additional articles in this collection, see http://perspectivesinmedicine.cshlp.org/cgi/collection/ 